\title{
A REPRESENTAÇÃO SOCIAL DO TRABALHO SOB A PERSPECTIVA DE TRABALHADORES DO CORTE DE CANA
}

\section{SOCIAL REPRESENTATION OF WORK UNDER THE PERSPECTIVE OF SUGAR CANE CUT WORKERS}

\author{
Luana Furtado Vilas Boas ${ }^{1}$
}

\begin{abstract}
RESUMO
O desenvolvimento e mudança das relações de trabalho permitiram um crescimento e diversidade em relação às suas formas. Sendo assim, o trabalho precário tem aumentado consideravelmente. Diante do exposto, o presente estudo buscou analisar a representação social do trabalho sob a perspectiva de cortadores de cana. Uma abordagem qualitativa foi utilizada nesta pesquisa. Para tal objetivo, foram realizadas entrevistas com quatro trabalhadores deste setor e a análise do discurso foi adotada para a análise dos dados coletados. Por fim, foi possível concluir que para estes sujeitos, o trabalho é tido primeiramente como artifício de sobrevivência, seguido pela necessidade de possuir dignidade perante a sociedade, sendo tratado como mecanismo para obtenção de conquistas e realizações pessoais e por último visto como obrigação e sofrimento.
\end{abstract}

PALAVRAS - CHAVES: Trabalho - Trabalho Precário - Representação Social - Cortadores de Cana.

\begin{abstract}
The development and change of labor relations allowed growth and diversity in relation to its forms. Thus, precarious work has increased considerably. Given the above, this study aimed to analyze the social representation of work from the perspective of cane cutters. A qualitative approach was used in this research. For this purpose, interviews were conducted with four workers in this sector and discourse analysis was adopted to analyze the data collected. Finally, it was concluded that for these subjects, work is seen primarily as artifice of survival, followed by the need to have dignity in society, being treated as a mechanism for obtaining achievements and personal accomplishments and last seen as an obligation and suffering.
\end{abstract}

KEYWORDS: Work - Precarious work - Social Representation - Cane Cutters

\section{INTRODUÇÃO}

O capitalismo, associado às constantes mudanças no contexto organizacional, advindas da globalização, acarretaram e ainda acarretam mudanças nas relações de trabalho, assim como nos próprios contratos de trabalho. Cada vez mais, o trabalho é requisitado e, ao mesmo tempo, "precarizado".

\footnotetext{
${ }^{1}$ Mestre em Administração pelo Programa de Pós Graduação em Administração da Universidade Estadual de Maringá (UEM), possuo MBA em Gestão de Pessoas pela UEM e sou graduada em Administração pela Universidade Estadual do Paraná (UNESPAR).

Revista Labor Fortaleza/CE, jan/jul 2017 Vol. 01, nº 17, p. 92-109 ISSN 1983-5000
} 
Silva e Freitas (2016) salientam que, com a redução do emprego estável de tempo integral, em decorrência de diversas formas de flexibilização, em termos de contratos, as formas flexíveis de trabalho ganharam força ao se mostrarem aplicáveis para lidar com as mudanças na esfera organizacional. Ao passo em que a precarização do trabalho afetou grandes contingentes de trabalhadores, a flexibilização, em termos de contratos, abalou o grupo de trabalhadores mais vulnerável: os de baixa renda (SILVA; FREITAS, 2016).

Neste ínterim, é possível associar o trabalho precário à incapacidade econômica e à instabilidade social e econômica, em que os excluídos social e economicamente possuem condições desprivilegiadas de vida, sendo suscetíveis à pobreza e à miséria (GEHLEN et al., 2011).

No entanto, conforme Morin (2001), quando se trata de trabalho é necessário compreender o que os sujeitos pensam quando falam dele, considerando cada contexto, além de ser importante entender que o trabalho pode ser percebido de diversas maneiras. Nesse aspecto, analisar as representações sociais sobre o trabalho que exercem é uma forma de compreender como os sujeitos são estruturados a partir dele e, ao mesmo tempo, estruturam sua realidade social. É importante destacar também que as representações sociais estão ligadas diretamente com o contexto ou grupo em que o sujeito está inserido e, neste sentido, podem ser interpretadas de formas diferentes de acordo com cada realidade social.

Diante desta perspectiva, cabem algumas inquietações: qual a representação social de trabalho para sujeitos que exercem o trabalho precário? Nesse sentido, o objetivo geral deste artigo é compreender a representação social de trabalho sob a perspectiva de sujeitos que exercem o trabalho precário: cortadores de cana. Para tanto, foram entrevistados quatro trabalhadores do setor sucroalcooleiro, moradores de Terra Boa - PR.

Para atingir tal objetivo, este estudo foi dividido em cinco partes, já incluindo a introdução. Na segunda parte, é apresentada uma breve revisão teórica acerca da representação social, seguida de trabalho e trabalho precário. Na terceira parte é identificado o método de pesquisa. Na quarta parte a análise é evidenciada e realizada a discussão dos resultados. Por fim, na quinta e última parte, é explicitada as considerações finais.

\section{A REPRESENTAÇÃO SOCIAL DE SERGE MOSCOVICI}

A percepção de representação social vem fomentando diversos debates em algumas áreas do conhecimento, como na Psicologia Social. No entanto, hoje sua ênfase se 
dá no campo das Ciências Humanas e Sociais, onde tal abordagem possui crescimento acelerado (JODELET, 2001). De acordo com a autora, esse movimento teve início na França com a instigação de Serge Moscovici, que é conhecido como um dos precursores da teoria das representações sociais.

Conforme Moscovici (1979), foi Durkheim o primeiro a propor a expressão "representação coletiva", com o objetivo de constituir a particularidade do pensamento social, em relação ao pensamento individual, compreendendo, assim, a representação individual como um fenômeno genuinamente psíquico, dividindo o sujeito do social.

Mas o que seria a representação social? A representação social, fundamenta-se em uma das vias de apreensão de mundo concreto, restrito em seus alicerces e em suas consequências (MOSCOVICI, 1979). O autor enfatiza ainda, que é necessário considerarmos a representação social como algo que possui um contexto psicológico autônomo, ao mesmo tempo em que é própria de nossa sociedade e de nossa cultura. Neste ínterim, a representação social pode ser entendida como algo natural, que integra nosso contexto social e cultural.

Jodelet (2001) afirma que as representações podem ser observadas nos discursos, pois ali circulam e são trazidas pelas palavras e veiculadas as mensagens e na mídia e, assim, são cristalizadas em condutas e organizações. Dessa forma, a linguagem pode ser vista não apenas como meio de comunicação, mas também como forma de construção de realidade social. Em relação à comunicação, Moscovici (1979) reforça que ela não se reduz apenas à transmissão das mensagens de origem ou ao transporte de informações inalteradas, mas também é capaz de diferenciar, traduzir, interpretar e combinar, reforçando o pressuposto de Jodelet (2001).

Nesse sentido, é importante destacar que a comunicação possui papel importante nas representações sociais. De acordo com Jovchelovitch (2002), os processos que engendram as representações sociais estão embebidos na comunicação e nas práticas sociais, tais como diálogo, rituais, padrões de trabalho e produção, arte e cultura. Desta forma, as representações são partilhadas a todo tempo na sociedade e contribuem para a construção do conhecimento.

De acordo com Jovchelovitch (2002), são as mediações que geram as epresentações sociais. Para a autora, a comunicação seria uma forma de mediação entre um mundo de perspectivas diferentes e ressalta que as mediações revelam numa ou noutra medida a procura de sentido e significado que marca a existência humana no mundo. Cada população possui seus modos dominantes de comunicação em relação a sua situação social e grau de instrução (MOSCOVICI, 1979). 
Para Jodelet (2001, pg. 22) a representação social "é uma forma de conhecimento, socialmente elaborada e partilhada, com um objeto prático, e que contribui para a construção de uma realidade comum a um conjunto social”. A autora salienta que as representações sociais enquanto sistemas de interpretação orientam e organizam as condutas e as comunicações sociais, possuindo potencialidade para intervir em alguns processos, tais como no desenvolvimento individual e coletivo e na definição das identidades tanto pessoais, quanto sociais.

Enquanto fenômenos cognitivos, as representações sociais englobam a pertença social dos sujeitos com as experiências normativas e afetivas, com as interiorizações de experiências, práticas e modelos de conduta socialmente manifestados pela comunicação social, tal qual possuem ligação (JODELET, 2001). Assim, as representações estão ligadas diretamente com o contexto ou grupo em que o sujeito está inserido, podendo ser interpretada de formas diferentes, de acordo com cada realidade ou contexto.

Corroborando, Spink (1998) reforça a importância de se considerar cada contexto e enfatiza que as representações sociais devem ser compreendidas no âmbito do meio que a constrói e a partir de sua funcionalidade nas interações sociais do cotidiano, não podendo ser reduzida apenas ao seu conteúdo cognitivo. $\mathrm{O}$ autor ressalta ainda que, sem a compreensão do contexto, não é possível entender as construções que origina. De acordo com Moscovici (1979), as pessoas possuem proposições distintas, conforme seus grupos, classes e culturas, o que justifica a nomenclatura "social", além do que, a representação social é construída coletivamente.

Deste modo, conforme Jovchelovitch (2002), o sujeito constrói na sua relação com o mundo, um novo mundo de significados de acordo com seu contexto. É por meio da sua relação com os outros que a representação acontece, permitindo uma mediação entre o sujeito e o mundo, permitindo sua descoberta ao passo em que possibilita sua construção. A autora ressalta ainda que é dentro e sobre essa rede que acontece a re-criação do sujeito, acerca do que já está lá. Sendo assim, sua tarefa é elaborar uma permanente tensão entre o mundo, que já se encontra constituído e seus próprios esforços para ser um sujeito (JOVCHELOVITCH, 2002).

\section{O "MUNDO" DO TRABALHO}


De fato, nos dias de hoje, acompanhamos uma constante transformação no mundo do trabalho. A tecnologia, associada à globalização permitem que as organizações se desenvolvam cada vez mais e em um curto período de tempo. Nesse contexto, ao passo em que o desenvolvimento organizacional acontece, o trabalho ou a "mão-de-obra" faz-se necessário para que tal processo realmente aconteça.

Para Borges e Yamamoto (2004), o trabalho deriva de necessidades naturais, mas realiza-se na interação entre os homens ou entre os homens e a natureza. No entanto, o surgimento do capitalismo permitiu uma concepção do trabalho que o exalta como sendo central na vida das pessoas, como o único meio digno de ganhar a vida, independente do seu conteúdo (BORGES; YAMAMOTO, 2004). Além da concepção do trabalho como algo central na vida das pessoas, a consolidação do capitalismo permitiu a modificação dos modos de produção, e a alteração de todo o estilo de vida e os valores sociais (CAMPOS; SARAIVA, 2014). Neste sentido, é possível apontar para discrepâncias em relação ao "mundo" do trabalho.

Conforme Morin (2001), ao mesmo tempo em que milhares de pessoas sofrem pela falta de uma vaga de emprego, outras sofrem pelo fato de terem que trabalhar excessivamente. Tal discrepância se justifica, pelo fato de que o trabalho conserva um lugar importante na sociedade (MORIN, 2001). Além de suprir necessidades básicas, como permitir o acesso à alimentação e satisfação de necessidades pessoais, o trabalho é visto como símbolo de dignidade e honestidade, ou seja, o sujeito enquanto trabalhador está livre do ócio e ocupa seu tempo de acordo com o que a sociedade julga ser correto.

Desta forma, não basta que o trabalho repercuta na vida particular do trabalhador, mas, além disso, deve representar algum valor na esfera social (CAMPOS; SARAIVA, 2014). Os autores ressaltam, ainda, que por mais que a remuneração seja um fator importante, sobretudo para a sobrevivência do sujeito, este não é o único elemento que os mantém ligados a um meio de produção.

No entanto, é importante ressaltar que o trabalho, bem como a forma de pensar sobre ele, é inerente às condições sóciohistóricas em que cada pessoa vive (BORGES; YAMAMOTO, 2004). Nesse sentido, de acordo com os autores, seu conceito dependerá do acesso que cada pessoa tem à tecnologia, da sua posição na estrutura social, das condições em que ela executa suas tarefas, das ideias e da cultura do seu tempo, dos exemplos de trabalhadores que cada uma tem em seu meio, entre outros, deixando claro que não existe uma homogeneidade em relação ao seu conceito. 
Borges e Yamamoto, (2004) apontam para as desigualdades de desenvolvimento no Brasil entre setores econômicos, regiões e organizações como fatores que favorecem o a existência de várias concepções de trabalho entre os sujeitos. Os autores ressaltam que cada sujeito possui seu próprio conceito de trabalho, o que permite uma grande variedade de conceitos e significados, ou seja, o trabalho é objeto de múltipla e ambígua atribuição de sentidos e significados.

Portanto, quando se fala de trabalho é necessário compreender o que os sujeitos pensam quando falam dele, considerando cada contexto e o fato de que pode ser depreendido de diversas maneiras (MORIN, 2001)

\section{UM "MUNDO" REAL: O TRABALHO PRECÁRIO}

Conforme Morin (2001), quando o assunto é trabalho, é importante compreender o contexto de trabalho a que nos referimos e desejamos entender. Para tanto, é necessário ressaltar que o foco deste estudo é compreender a representação social de trabalho, no entanto, partindo de trabalhadores que estão imersos no mundo do trabalho precário: os cortadores de cana.

A definição de "trabalho precário" é um tanto quanto complexa, pois existe divergência em relação ao conceito do que vem a ser "precário", pois, conforme Sá (2010), cada país possui um conceito distinto em relação à precariedade. Para Kalleberg (2009), a diferença existente em cada país, depende de seu estágio de desenvolvimento, instituições sociais, culturas e outras diferenças nacionais.

Kalleberg (2009) entende trabalho precário como um trabalho incerto, imprevisível, no qual os riscos empregatícios são assumidos principalmente pelo trabalhador, e não pelos seus empregadores ou pelo governo. Sá (2010) associa o trabalho precário a quatro características, a saber: a) Insegurança no emprego; b) Perda de regalias sociais; c) Salários baixos; d) Descontinuidade nos tempos de trabalho. Nesse sentido, é possível associar o trabalho precário à incapacidade econômica e instabilidade social e econômica, onde os excluídos social e economicamente, possuem condições desprivilegiadas de vida, sendo suscetíveis à pobreza e à miséria (GEHLEN, et. al 2011)

De acordo com Kalleberg (2009), o trabalho precário tem aumentado nas últimas

décadas devido à globalização. Para o autor, a globalização tem acarretado em 
interdependência econômica, maior comércio internacional e movimento acelerado do capital, produção e trabalho, o que fomenta o aumento da precarização.

É importante destacar que o crescimento do trabalho precário é prejudicial para os sujeitos enquanto trabalhadores, sujeitos sociais e humanos. Para Kalleberg (2009), o trabalho precário é deteriorante, pois acarreta em diversas consequências negativas para os trabalhadores, famílias e sociedade. De acordo com o autor, este tipo de trabalho produz insegurança econômica e volatilidade econômica para trabalhadores e famílias, além do que, contribui para a crescente desigualdade econômica, reforçando os sistemas distributivos altamente desiguais e injustos.

\section{COMPREENDENDO A REPRESENTAÇÃO SOCIAL DE TRABALHO SOB A PERSPECTIVA DOS CORTADORES DE CANA}

Com o intuito de desvelar o mundo do trabalho, bem como compreender a representação social deste sob a perspectiva dos cortadores de cana, a abordagem qualitativa foi utilizada, por permitir ir além dos dados, ao mesmo tempo em que possibilita o entendimento do fenômeno na sua complexidade (GODOY, 1995).

Para coleta de dados, foram realizadas entrevistas semiestruturadas, com quatro trabalhadores do setor sucroalcooleiro, que trabalham com o corte da cana. Tais entrevistados são homens, pais de família, com idade entre 45 e 60 anos. Dos quatro entrevistados, nenhum possui o ensino médio concluído. Os entrevistados residem em Terra Boa, uma cidade do interior do Paraná e trabalham em usinas de cana de açúcar localizadas na região deste município.

É importante mencionar que um destes trabalhadores encontra-se aposentado de suas funções, entretanto, exerceu a atividade de cortador de cana durante muitos anos de sua vida. Tal entrevistado forneceu depoimentos significativos que contribuíram imensamente para uma melhor compreensão do fenômeno em questão.

Para a análise dos dados, foi utilizada a análise do discurso, considerando a vertente francesa. Segundo Orlandi (2007) o discurso seria a palavra em movimento, ou seja, a prática de linguagem em si, de modo que a análise do discurso consiste na compreensão do sentido da linguagem, visando compreender como os objetos simbólicos produzem sentidos, como ele está investido de significância para e por sujeitos. Partindo dessa perspectiva, a análise do discurso permitirá a análise acerca dos dados coletados e possibilitará o alcance do 
objetivo deste estudo, que consiste em compreender a representação social de trabalho para os cortadores de cana.

\section{O CONTEXTO}

O primeiro entrevistado foi o Sr. José Luiz. Domingo foi o dia escolhido para as entrevistas, pois os entrevistados trabalhavam durante a semana e, assim, tinha maiores chances de encontrá-los em casa. O Sr. José Luiz, veio juntamente com sua esposa realizar a recepção, momento que foi utilizado para explicar sobre a pesquisa. Logo, fez o convite para que entrasse em sua residência, bastante simples, porém, muito bem cuidada e aconchegante.

Desde o início, apresentou certa timidez e medo em responder as perguntas, porém, o Sr. José Luiz foi se mostrando bastante seguro no decorrer da entrevista. No final da entrevista, com muito boa vontade, o Sr. José Luiz se prontificou e indicou outras três pessoas, trabalhadores do setor do corte de cana, que eram seus amigos e que moravam nas proximidades do bairro. O trabalhador acompanhou-me até a casa do Sr. Oliveira, onde foi realizada a segunda entrevista.

O Sr. Oliveira demonstrou-se menos receptivo, talvez por não me conhecer. Recebeu-me do outro lado do portão, e somente depois da devida apresentação destrancou o portão e fez o convite para que entrasse. Havia certa desconfiança no começo da entrevista, no entanto, foi um dos trabalhadores mais desenvoltos em relação às perguntas realizadas.

A terceira entrevista foi realizada com o Sr. Zezinho, o qual me recebeu com bastante bom humor. À primeira vista, pareceu ser um senhor muito simpático e ao mesmo tempo extremamente simples.

A quarta entrevista foi realizada com o Sr. Devanir, já aposentado de suas funções, mas que demonstrou muito interesse em participar da pesquisa. Extremamente receptivo, recebeu-me com muita hospitalidade juntamente com sua esposa, fazendo questão de explicar cada detalhe de sua história, até se emocionando no decorrer da entrevista. As marcas na pele, e mãos (que fez questão de mostrar) representam quão sofrida e batalhada foi sua trajetória. O Sr. Devanir insistiu em apresentar um dos seus EPI's (Equipamento de Proteção Individual), utilizado em sua época de "corte de cana", para ele, este equipamento simboliza toda sua trajetória no "corte". 
Em suma, todos os trabalhadores em sua simplicidade, cada qual do seu jeito, demonstraram receptividade e disposição em contar um pouquinho de sua história. A seguir, serão explicitados trechos das entrevistas, sendo que foram considerados os que mais forneceram subsídios para a análise.

\section{“O QUE É TRABALHO?” A PERSPECTIVA DOS TRABALHADORES DO CORTE DE CANA}

De origem pobre, o Sr. José Luiz aprendeu o que é trabalho com os pais, a quem ajudava desde criança no campo:

001: Quem ensinou foi meu pai e minha mãe, aí eu comecei a trabalhar e foi levando assim, foi aprendendo, né? (...) Ai, nós ia na roça assim, e nós começava a carpi, nós ajudava eles a plantar. Eles ia plantando e nós ia tampando aquelas covas (...).

No fragmento discursivo 001, fica claro que o trabalhador é de origem pobre e que trabalha desde criança com os pais no campo, assim como todos os outros entrevistados. "A roça", então, foi o primeiro e único tipo de trabalho praticado pelo entrevistado, não possuindo oportunidade, nem condição social para praticar ou aprender outra atividade, pois desde cedo, aprendeu o "trabalho do campo" com os pais. Fica implícito, nesse fragmento discursivo, que devido ao trabalho o Sr. José Luiz não teve a oportunidade de estudar.

Tal fato pode ser esclarecido por Silva e Freitas (2016), quando ressaltam que os trabalhadores de baixa renda, em sua maioria possuem famílias orientadas para o trabalho duro e uma vida de circunstâncias difíceis, necessitando iniciar suas vidas profissionais logo cedo para complementar ou assegurar o próprio sustento. Entretanto, esses sujeitos contam com uma instrução educacional deficitária, sendo que em si, o estudo deficitário ou a falta dele é um dos grandes responsáveis pela perpetuação das difíceis condições de vida vivenciadas por esses trabalhadores (SILVA; FREITAS, 2016).

O Sr. Oliveira também teve contato com o trabalho desde criança, da mesma forma que o Sr. José Luiz:

002: O trabalho mesmo eu aprendi com, com a minha família, com meu pai, meu irmão mais velho. Eu vim da..., praticamente da roça, né? Nasci na roça, e então eu aprendi a lidar com a roça, morava no sítio, tomava conta de café com a minha família. Meu pai era "porcenteiro" no caso, a gente foi crescendo e "veio" pra cidade. Não tinha outra opção de serviço, pouco estudo, as condições financeiras da 
gente era bem fraca, restava só a roça. Voltamos pra roça de novo, morava na cidade, mas trabalhava na roça. Naquele tempo chamava de bóia fria.

No fragmento discursivo 002 fica evidente o contexto do entrevistado. Nasceu e foi criado no campo, trabalhando no meio rural junto com a família. No trecho "não tinha outra opção de serviço" fica explícita a falta de oportunidade em decorrência do "pouco estudo" e "condição financeira fraca", justificando a escolha pela "roça" determinada pela sua condição social. No trecho "só restava a roça" tal afirmação fica visível, ou seja, em decorrência da falta de oportunidade e condição social, o trabalho na "roça" lhe foi imposto. No trecho "o trabalho mesmo eu aprendi com a minha família" fica implícito em "mesmo" a ideia de que trabalho "verdadeiro" é o trabalho no campo, ou seja, tem-se a concepção de trabalho, como trabalho operacional ou que exija esforço físico.

Quando perguntado sobre a importância do trabalho, ficou explícita a necessidade de todos para com este compromisso. Tal necessidade se dá pela obrigação de sustento da família e pela busca da própria sobrevivência:

003: A gente precisa pra ganha aquele dinheiro, porque, pra viver, né? Porque se
num trabalhar eu acho que num.tem que trabalhar pra viver, né?
004: A importância de eu trabalhar é que eu consigo dinheiro "pra mim" comprar
minhas coisas, né, pra comer, pra viver, pra "mim tratar" da família, né? Eu acho
que..., eu acho que é assim, né? Que sem eu trabalhar eu não vou conseguir nada, se
depender de sorte ... (risos)
005: Olha, uma coisa que assim, igual eu falei pra você, o trabalho pra mim é tudo!
Eu dependo do trabalho, eu vivo do trabalho. Eu acho que se for pra "mim" ficar
parado eu num conseguiria viver aí, nem um mês. O que significa o trabalho pra
mim? É minha vida.

Os fragmentos discursivos 003, 004 e 005 são reveladores. Aqui fica explícita a concepção de trabalho como artifício de sobrevivência, "tem que trabalhar pra viver". Quando o entrevistado justifica a importância do trabalho, "pra comer, pra viver, pra tratar da família" fica implícito, que o trabalho representa uma forma de "ganhar dinheiro" para que o trabalhador consiga suprir suas necessidades básicas. No fragmento discursivo 003, quando o entrevistado diz "a gente precisa trabalhar pra ganhar aquele dinheiro" é possível compreender que o trabalho do corte de cana, oferece baixa remuneração, sendo "aquele dinheiro" o suficiente apenas para a sobrevivência.

Nos fragmentos discursivos 004 e 005, é defendida a ideia de inexistência de vida sem o trabalho, ficando explícita a dependência do trabalho para a sobrevivência, além do que o trabalho é visto como "tudo" e condição para a "vida". 
Os entrevistados possuem um discurso muito forte em relação ao trabalho como enobrecimento. Reproduzindo a ideologia de que "tem que trabalhar para ter dignidade":

006: Ah, porque eu acho que é "mió" eu trabalhar do que partir "pro" lado errado, né? Porque se eu não trabalhar aí eu vou ter que partir pro lado... lado errado. Ou roubar, ou bagunçar, ou depender dos outros, né? Pra mim eu acho que é importante.

007: É o seguinte, pra mim o trabalho, ele edifica qualquer pessoa. Edifica e ensina a pessoa a viver (tempo). Foi assim que eu aprendi, os meus pais me ensinaram desse jeito a trabalhar. Vai te sustentar, sustentar a tua família, você não vai adquirir coisa errada, e tenho certeza, tanto a mim quanto a qualquer pessoa, ele "tano" trabalhando, ele não tá pensando em maldade.

008: Ah, o trabalho é bom, né? Porque ensina muita coisa, porque se a pessoa não trabalha aí vira "vagabundo", só aprende coisa que não presta, né? Então, quer dizer, o trabalho é a coisa "mió" que tem, é o trabalho, né? A pessoa tendo saúde, né? A pessoa que não trabalha só vai inventar o quê? (risos) Você tendo seu serviço não tem coisa "mió", não é mesmo? Porque se você não tem um serviço fica "vadio", né? Fica "vadio", e tendo um serviço você levantou cedo, lavou o rosto, bebeu um cafezinho,... pra roça trabalhar (risos).

Conforme Campos e Saraiva (2014), a remuneração não é o único elemento que mantem os sujeitos ligados a um meio de produção, ou seja, por mais que o trabalho seja essencial à sobrevivência também deve representar algum valor na esfera social. Nos fragmentos discursivos 006, 007 e 008 é evidente a concepção de trabalho como sinônimo de dignidade. Neste trecho "é melhor trabalhar do que partir pro lado errado" é combatida a ideia de não trabalho, deixando implícito com o "lado errado", uma possível entrada para o crime com a ausência do trabalho, e adotada a concepção de trabalho como qualificação de um sujeito que é honesto e digno. Aqui, o trabalho é defendido como central na vida dos sujeitos, ficando explícita a condição de "trabalho ou crime", devido às condições sociais precárias dos entrevistados. No trecho "ensina a pessoa a viver" é silenciado o sofrimento em relação ao trabalho, reproduzindo um discurso social de que a pessoa deve sofrer para aprender a viver. No final desta frase, Sr. Oliveira se manteve em silêncio, com o olhar distante, o que permite a interpretação de que o sofrimento fez ou faz parte de sua história, e que foi desta forma que aprendeu "o que é a vida".

Além do trabalho como sinônimo de dignidade, a representação do trabalho como mecanismo de conquista pessoal é muito forte:

009: Tudo que eu tenho, graças a Deus, é do trabalho, o esforço do trabalho. Eu não tenho nada adquirido assim, "ai eu adquiri isso aqui num jogo, adquiri isso aqui num ... qualquer outra coisa", tudo veio do trabalho. Num tenho nada praticamente, 
graças a Deus tenho a família, a esposa, meus filhos, né? Mais a casinha, um

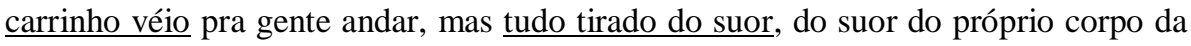
gente.

010: (Importância do trabalho) Muito importante! Porque quando eu cheguei aqui, eu conversei com o..., ele disse: vamos entrar na Companhia Melhoramentos do Paraná. Rapaz, essa época que eu morava no sítio, eu nunca tive o prazer de fazer uma compra, tá? E desde que eu cheguei aqui, nesse barraco que eu moro, abençoado por Deus, aí eu fui fazer uma compra, entendeu? Nossa, foi um tudo! Né, Marli (esposa)?

No fragmento discursivo 009, o Sr. Oliveira reforça que não conquistou muita coisa com o trabalho, deixando implícita a má remuneração do trabalho no corte de cana, mas "a casinha, carrinho véio" representa uma conquista pessoal de grande significado para o entrevistado, pois "veio do trabalho" e foi "tirado do suor" defendendo o trabalho como ferramenta de conquistas, pois não foi adquirido de forma "fácil" como "num jogo", combatendo a idealização de dinheiro fácil. Neste ponto, o sofrimento oriundo do trabalho é a razão das poucas conquistas do entrevistado, e que para o Sr. Oliveira representa muito.

O Sr. Devanir se emocionou durante a entrevista ao relembrar o sofrimento que passou durante seus anos de trabalho. No fragmento discursivo 010, fica claro que o trabalho lhe permitiu conquistas simples, mas que sem o qual, isso não lhe seria possível. O entrevistado relata sua vinda do campo para a cidade, deixando implícito que no campo suas condições eram extremamente precárias: "eu nunca tive o prazer de fazer uma compra". O fato de ter adquirido um emprego na cidade, com o corte de cana, lhe possibilitou a simples realização pessoal de "fazer uma compra", que de acordo com ele e com a esposa (no trecho, ele confirma com a esposa, que balança a cabeça, dizendo que sim) "foi tudo".

Por mais que o trabalho tenha possibilitado a realização de conquistas pessoais, Sr. Devanir considera o trabalho como sinônimo de obrigação e sofrimento, ao ponto de se comparar a um "escravo". Ao relatar sua experiência, se emociona e chora:

011: Eu vivia brincando, aí meu pai comprou uma chácara, aí eu fui trabalhar. Rapaz, aquelas 'formiga' mordia meu pé. Aquele sol quente. Aí eu via como que a vida era difícil.

012: (Pensamento acerca do trabalho) Nossa! Muito sofrimento. Muito. Foi tanto que pra falar bem a verdade pra você, quando eu fui fazer a entrevista sobre aposentadoria, aí o cara falou: Nossa, mas você não é preto! Como é que você 'ponhou' escravo? Olha! você já pensou? Rapaz, eu fui escravo do meu pai, por que pra começar a trabalhar com dez anos e meio é escravo, né? E eu fui escravo da empresa, porque... "cortar cana"? Portanto, se você quiser eu vou arrumar um EPI. Foi o primeiro corte de cana que existiu.

013: Mas, olha, que nem eu tô falando pra você (...) pra você ter um exemplo: eu almocei, naquela época, nove horas, e fui tomar água uma e meia da tarde. $\mathrm{O} \underline{\text { suor }}$ 
corria assim, tá? Coisa que você nem sabe o que é suar, coisa que você não precisa também, né? Bom. Mas ó rapaz, é terrível, tá?

Sofrimento. É este o termo que fica evidente no discurso acerca do trabalho para este entrevistado nos fragmentos discursivos 011, 012 e 013. O trabalho imposto como obrigação fica implícito no "eu vivia brincando", ou seja, o entrevistado era feliz por não trabalhar, era criança, até que o pai “comprou uma chácara". "Aí eu via como a vida era difícil" representa todas as dificuldades do entrevistado com o trabalho. Pelo fato de o trabalho ser sofrido, e ao mesmo tempo uma necessidade e uma obrigação, a vida passa a ser “difícil". A “formiga" e o "sol” são figuras que ilustram esse sofrimento. Conforme Gehlen, et al (2011) o trabalho precário gera a incapacidade econômica e instabilidade social e econômica, onde os excluídos social e economicamente, possuem condições desprivilegiadas de vida, sendo suscetíveis a pobreza e miséria.

O Sr. Devanir se compara a um "escravo" explicitando seu sofrimento com o trabalho no fragmento discursivo 012. O Sr. Devanir se levantou e fez questão de apresentar um EPI utilizado na época de trabalho com o corte de cana. O EPI era uma caneleira, pesada e desgastada pelo constante uso durante muitos anos de trabalho. Este equipamento simboliza o trabalho e todo o sofrimento passado pelo entrevistado, pois ao apresentar o EPI, o Sr. Devanir entrou em prantos. Para ele, o suor representa o trabalho e ao dizer "você nem sabe o que é suar" e que "você não precisa" deixa implícito que para ele "não sabemos o que é trabalhar", pois trabalho mesmo seria o trabalho realizado por ele, ou seja, o trabalho pesado; e deixa implícito que para ele, o trabalho é uma questão de necessidade. A palavra "terrível" simboliza exatamente o sentimento do Sr. Devanir em relação ao trabalho.

Um fato interessante, é que dos quatro entrevistados, apenas o Sr. Oliveira, defendeu o trabalho praticado, não reclamando em nenhum momento, ou seja, silenciando a precariedade e sofrimento do trabalho no corte de cana:

\begin{abstract}
014: Muita gente pensa que o trabalho da roça é uma coisa, bicho de sete cabeças, é uma monstruosidade, é uma coisa que prejudica a pessoa. Eu já falo que, qualquer tipo de trabalho, seja um datilógrafo, seja um escritor, seja um músico, seja o que for, tudo é trabalho. Mas pra mim o trabalho mais importante é o da roça, cortador de cana, o carpidor de café, o plantador de mandioca (...) Porque é de lá, que vem o nosso sustento! É lá da roça que vem o nosso sustento.
\end{abstract}

Nesse fragmento discursivo, o entrevistado silencia uma possível revolta e preconceito em relação ao seu trabalho com o corte de cana. Ao relatar que "muita gente pensa que o trabalho da roça é um bicho de sete cabeças, é uma monstruosidade" dissemina o 
que já ouviu em relação ao seu tipo de trabalho, deixando implícito que existe discriminação em relação ao trabalho praticado, no entanto, como forma de fuga, reproduz o que lhe foi ensinado: "o trabalho mais importante é o da roça" justificando sua condição social e sua incapacidade de mudança, frente a sua realidade social precária, de sofrimento e de poucas oportunidades.

Silva e Freitas (2016) consideram a "baixa renda" como precondição social para as seguintes dimensões: estrutura familiar, dimensão educacional e a vida profissional precoce e precária. Entretanto, tais dimensões refletem diretamente no desenvolvimento e estrutura de vida desses sujeitos, podendo até mesmo, de certa forma, serem visualizadas como um ciclo.

015: (Em relação ao trabalho) Bom, uma parte é boa. Uma parte é boa porque o seguinte (...) O trabalho é uma coisa legal, que você trabalha, você se sente bem. Você tá entendendo? Que você tá junto com seus amigos, tudo pobre na verdade, né? Um conta uma história, outro conta outra história, e você vai passando o dia.

No fragmento discursivo 015 também foi possível identificar um tipo de fuga da realidade. O Sr. Devanir relata que "uma parte é boa", combatendo que o trabalho não é tão ruim assim, por possuir uma "parte boa". Os amigos seria uma forma de dispersão e fuga da precária realidade do trabalho, e "tudo pobre" deixa implícito que Devanir se sente bem com outras pessoas de sua mesma classe social, ou seja, são pessoas que possuem a mesma necessidade e passam pelo mesmo tipo de sofrimento. O trecho "vai passando o dia" defende o interesse de que o dia termine logo, ou seja, demonstra a infelicidade em relação ao seu trabalho e a sua realidade no âmbito do profissional.

De uma maneira geral, diante da análise dos dados, foi possível compreender que a representação social do trabalho para os trabalhadores do corte de cana consiste em:

Quadro 1: Representação social do trabalho para os cortadores de cana.

\begin{tabular}{|l|l|}
\hline Representação social identificada & \multicolumn{2}{c|}{ Elementos discursivos } \\
\hline Trabalho como artifício de sobrevivência & -Trabalho como necessidade primária para \\
sobrevivência; \\
-Trabalho como sendo "tudo" na vida; \\
\hline -Trabalho como forma de aquisição de \\
suprimentos básicos, como alimentação.
\end{tabular}




\begin{tabular}{|c|c|}
\hline Trabalho como sinônimo de dignidade & $\begin{array}{l}\text {-Trabalho como desvio do ócio; } \\
\text {-Trabalho como sendo edificador; } \\
\text {-Trabalho como requisito para manter-se do "lado } \\
\text { do bem" (não roubar, ou praticar crimes). }\end{array}$ \\
\hline Trabalho como mecanismo de conquistas pessoais & $\begin{array}{l}\text {-Trabalho como forma de aquisição de capital; } \\
\text {-Trabalho como mecanismo de conquistas } \\
\text { materiais (casa, carro); } \\
\text {-Trabalho como mecanismo de conquista pessoal } \\
\text { (oportunidade de realizar uma compra, ter e manter } \\
\text { uma família). }\end{array}$ \\
\hline $\begin{array}{l}\text { Trabalho como sinônimo de obrigação e } \\
\text { sofrimento }\end{array}$ & $\begin{array}{l}\text {-Má remuneração; } \\
\text {-Condições ruins de trabalho; } \\
\text {-Trabalho pesado como obrigação e necessidade; } \\
\text {-Privação de desenvolvimento pessoal (estudo); } \\
\text {-Impossibilidade de escolhas e oportunidades. }\end{array}$ \\
\hline $\begin{array}{l}\text { Trabalho operacional/pesado como trabalho } \\
\text { "verdadeiro" }\end{array}$ & $\begin{array}{l}\text {-Trabalho exige suor; } \\
\text {-Trabalho do campo (operacional) como o mais } \\
\text { importante. }\end{array}$ \\
\hline
\end{tabular}

Fonte: Elaborado pela autora.

É importante destacar que tais representações foram as que mais se destacaram e se repetiram dentre os discursos dos trabalhadores. Como todos são oriundos do campo, tiveram contato com o trabalho desde cedo, aprendendo com os pais apenas este tipo de trabalho. Para tanto, o trabalho do campo é considerado por eles o mais importante, devido ao contexto e desenvolvimento histórico e social desses sujeitos. De forma geral, esses trabalhadores consideram que o trabalho exige esforço físico, ou seja, compreendem o trabalho como algo meramente operacional, ou seja, para eles o trabalho é visto como trabalho "pesado".

Sendo assim, o trabalho para esse grupo de trabalhadores é tido primeiramente como artifício de sobrevivência, seguido pela necessidade de possuir dignidade perante a sociedade, sendo tratado como mecanismo para obtenção de conquistas e realizações pessoais e por último visto como obrigação e sofrimento. 


\section{CONSIDERAÇÕES FINAIS}

Conforme salienta Spink (1998), a representação social deve ser compreendida em seu contexto, no âmbito do meio que a constrói, pois que sem a compreensão de seu contexto não é possível entender as construções que origina. Sendo assim, quando se fala de trabalho é importante entender o que os sujeitos pensam quando falam dele, considerando cada contexto e o fato de que pode ser compreendido de várias maneiras (MORIN, 2001). Nesse sentido, o objetivo deste trabalho era de compreender a representação social de trabalho sob a perspectiva de trabalhadores do corte de cana, sendo tal propósito realizado com êxito.

Conforme visto no referencial teórico deste trabalho, o capitalismo permitiu que o trabalho fosse visto como central na vida do homem, sendo que, somente exercendo alguma atividade remunerada o sujeito seria considerado socialmente aceito em decorrência de diversos fatores, além do que, torna-se ferramenta principal para aquisição de capital e sobrevivência. O intuito, a partir de então, era de desvendar o "mundo" do trabalho dos cortadores de cana, ou seja, compreender a representação social de trabalho diante de seu contexto histórico e cultural, que conforme destacamos, é precário e limitador.

Todos os entrevistados são naturais do meio rural, nasceram e foram criados no campo, aprendendo a atividade do trabalho desde pequenos com os próprios pais. A necessidade e o contexto social dos próprios pais fez com que ensinassem o ofício do trabalho para os filhos, para que conseguissem o sustento e melhores condições de vida. Sendo assim, o trabalho do campo ou na "roça" como é relatado pelos entrevistados foi o único que tiveram a oportunidade de conhecer, sendo privados de elementos básicos para o desenvolvimento de qualquer pessoa, como o estudo e a vivência da própria infância.

É nesse contexto que a representação social do trabalho para estes homens não é muito favorável, sendo compreendido como uma obrigação, além do que, é acompanhado de sofrimento frente à precária realidade social destes sujeitos. Ao mesmo tempo, para eles, o trabalho é necessário, pois implica em "ter dignidade", possibilita conquistas pessoais, ao passo em que é essencial para a própria sobrevivência e manutenção da família.

Neste ínterim, este estudo não permitiu apenas uma compreensão da representação social do trabalho para este grupo de trabalhadores, além disto, possibilitou a compreensão do que vem a ser o "mundo" destes sujeitos, praticantes do trabalho precário, limitados por uma condição social desfavorável. Tal "mundo" é penoso, mas possibilita que esses sujeitos possam manter suas vidas e a estrutura familiar, de maneira simples, dentro de suas 
possibilidades e que tenham o mínimo para a sobrevivência e construção de uma vida digna e "feliz".

\section{REFERÊNCIAS}

BORGES, L. O.; YAMAMOTO, O. H. O mundo do trabalho. In: ZANELLI, J. C., ANDRADE-BORGES, J. E.; BASTOS, A. V. B. (Org.). Psicologia, organizações e trabalho no Brasil. Porto Alegre: Artmed, 2004.

CAMPOS, M.; SARAIVA, L. A. S. O trabalho, suas representações e sentidos: da demissão à recontratação de trabalhadores. Revista Economia \& Gestão, v. 14, n. 36, p. 31-56, 2014.

GEHLEN, V. R. F; RAIMUNDO, V. J.; VASCONCELOS, R. C.; ALENCAR, M. M. C. M. O Trabalho precário e a saúde precarizada da mulher: uma abordagem sobre as condições sociais das trabalhadoras nas unidades domésticas de produção de confecções de vestuário e acessórios em Toritama-PE. Revista da RET, Rede de Estudos do Trabalho. Ano V Número 9 - 2011.

GODOY, A. S. Introdução à pesquisa qualitativa e suas possibilidades. RAE - Revista de Administração de Empresas, São Paulo, v. 35, n. 2, p. 57-63, mar./abr. 1995.

JODELET, D. Representações sociais: um domínio em expansão. In: JODELET, D. (Org.). As representações sociais. Rio de Janeiro: EdUERJ, 2001. p.17-44.

JOVCHELOVITCH, S. Vivendo a vida com os outros: intersubjetividade, espaço público e representações sociais. In: GUARESCHI, Pedrinho; JOVCHELOVITCH, Sandra. Textos em representações sociais. Petrópolos: Vozes, 1998. P. 63-85.

KALLEBERG, A. L.. O crescimento do trabalho precário: um desafio global. Rev. bras. Ci. Soc. [online]. 2009, vol.24, n.69, p. 21-30. ISSN 1806-9053.

MOSCOVICI, S. A representação social da psicanálise. Rio de Janeiro: Zahar, 1978.

MORIN, E. M. Os sentidos do trabalho. Revista de Administração de Empresas, São Paulo, v. 41, n. 3, p. 8-19, jul./set. 2001.

ORLANDI, E. P. Análise do discurso: princípios e procedimentos. Campinas: Pontes, v. 7. 2007.

SILVA, A. L.; FREITAS, E. F.; Para além dos critérios econômicos do trabalho de baixa renda no Brasil. O\&S. Salvador. v. 23, n. 76, p. 037-056, Jan./Mar. 2016

SPINK, Mary Jane. Desvendando as teorias implícitas: uma metodologia de análise das representações sociais. In: GUARESCHI, Pedrinho; JOVCHELOVITCH, Sandra. Textos em representações sociais. Petrópolis: Vozes, 1998. p. 117-145. 
SÁ, T. «"Precariedade" e "trabalho precário": consequências sociais da precarização laboral », Configurações [Online], 7 |2010, posto online no dia 18 Fevereiro

2012,Disponível em: <http:// configuracoes.revues.org/203>. Acesso em: 10 dez. 2015. 